\title{
Grãos secos de destilaria com solúveis, aplicação em alimentos e segurança: Revisão
}

\author{
$\underline{\text { Juliana Regina da Silva }}^{\mathbf{1}^{*}}{ }^{\text {Diego Peres Netto }}{ }^{\mathbf{2}}$ : Vildes Maria Scussel $^{\mathbf{1}}$ \\ ${ }^{1}$ Laboratório de Micotoxinas e Contaminantes Alimentares, Departamento de Ciência e Tecnologia de \\ Alimentos, Centro de Ciências Agrárias, Universidade Federal de Santa Catarina, Florianópolis, Santa \\ Catarina, Brasil; \\ ${ }^{2}$ Departamento de Zootecnia e Desenvolvimento Rural, Centro de Ciências Agrárias, Universidade Federal de \\ Santa Catarina, Florianópolis, Santa Catarina, Brasil \\ * Autor para correspondência, E-mail:juliana.zootecnista@hotmail.com
}

\begin{abstract}
RESUMO. Grãos secos de destilaria com solúveis (DDGS) são coprodutos da indústria de etanol que utiliza milho como matéria prima. Devido à sua composição nutricional com alto teor de proteínas e fibras, aliado a baixo custo, os DDGS têm sido utilizados na produção de ração animal, embora ainda pouco conhecido no Brasil para essa aplicação, bem como em alimentos para humanos. Com o aumento do uso de DDGS à nivel internacional, especialmente sua inclusão na alimentação animal, tem havido uma preocupação com sua segurança quanto à proliferação de bactérias, fungos, formação de micotoxinas, além de outros tipos de contaminantes. O objetivo desta revisão é relatar as características de processamento do DDGS, sua composição nutricional, possíveis aplicações e especialmente a sua segurança (contaminantes biológicos e químicos).
\end{abstract}

Palavras chave: Alimentos, contaminantes, DDGS, etanol, milho, nutrição animal

\section{Dried distillers grains with soluble, food applications and safety: Review}

\begin{abstract}
Dried distillers grains with soluble (DDGS) are co-products of the ethanol industry using corn as a feedstock. Because of its nutritional composition with high content of protein and fiber, combined with low cost, DDGS has been used in animal feed production, although still little known in Brazil for this application, as well as in humans for food. With the increased use of DDGS to the world stage, particularly their inclusion in animal feed has been a concern for their safety as the proliferation of bacteria, fungi, formation of mycotoxins and other types of contaminants. The objective of this review is to report the processing characteristics of DDGS, its nutritional composition, possible applications and especially their safety (biological and chemical contaminants).
\end{abstract}

Keywords: Animal nutrition, contaminants, corn, DDGS, ethanol, food

\section{Introdução}

Nos últimos anos a demanda pela produção de combustíveis limpos (etanol, diesel e gás), conhecidos como bio combustíveis, tem levado os países industrializados a desenvolverem suas próprias tecnologias. Dentre eles, a produção mundial de etanol tem apresentado aumento crescente, de maneira que países como os Estados Unidos pretendem intensificar sua produção nos próximos anos (Corrêa, 2006). Diversos fatores contribuem para esse fenômeno, tais como a necessidade, Conforme Gurgel (2001):

a. Fomentar fontes de energia de menor impacto no meio ambiente (capazes de reduzir emissões de gases de efeito estufa);

b. Aumentar a segurança energética;

c. Reduzir a dependência de importações de petróleo.

Um coproduto das indústrias de etanol utilizando o milho como matéria prima é conhecido com a sigla DDGS (dried distillers grains with solubles), ou seja, em português - 
grãos secos de destilaria com solúveis - o qual possui elevado teor de proteína e fibra, com utilização na alimentação animal (Brito, 2008). No entanto, tem havido uma preocupação com sua segurança quanto à proliferação de bactérias e fungos, formação de micotoxinas além de outros tipos de contaminantes provenientes da matéria prima utilizada e/ou processamento aplicado, sendo de extrema importância o estudo de sua segurança na aplicação em alimentos (Zangh et al., 2009; Khatibi et al., 2014).

\section{Etanol e resíduos de produção}

A produção de etanol se dá a partir da fermentação de amido ou açúcares de diversas matérias primas (amiláceas e açucareiras) sendo que os mais ricos em amido ou açúcar apresentam maior rendimento em etanol (Leite \& Leal, 2007). A produção com base de açúcares, como é o caso da cana de açúcar, é mais simples quando comparada com a produção com base em matérias amiláceas, como o milho e trigo, e celulósica, como o bagaço da cana (Figura 1). No caso de matérias amiláceas ou celulósicas, há a necessidade da sua transformação preliminar em açúcares simples por ação de enzimas e ácidos, enquanto que na cana os açúcares já estão disponíveis na biomassa (BNDES \& CGEE, 2008). Nos Estados Unidos, atual maior produtor, o milho é o principal alimento usado como substrato. No Canadá e na Europa são utilizados trigo e cevada. No Brasil, segundo maior produtor mundial de etanol, o principal substrato da produção é a cana de açúcar (Ribeiro et al., 2010). Contudo, em períodos de baixa safra, que compreende o período de dezembro a março, o milho tem sido utilizado como fonte de carboidratos no país (SNA, 2014).

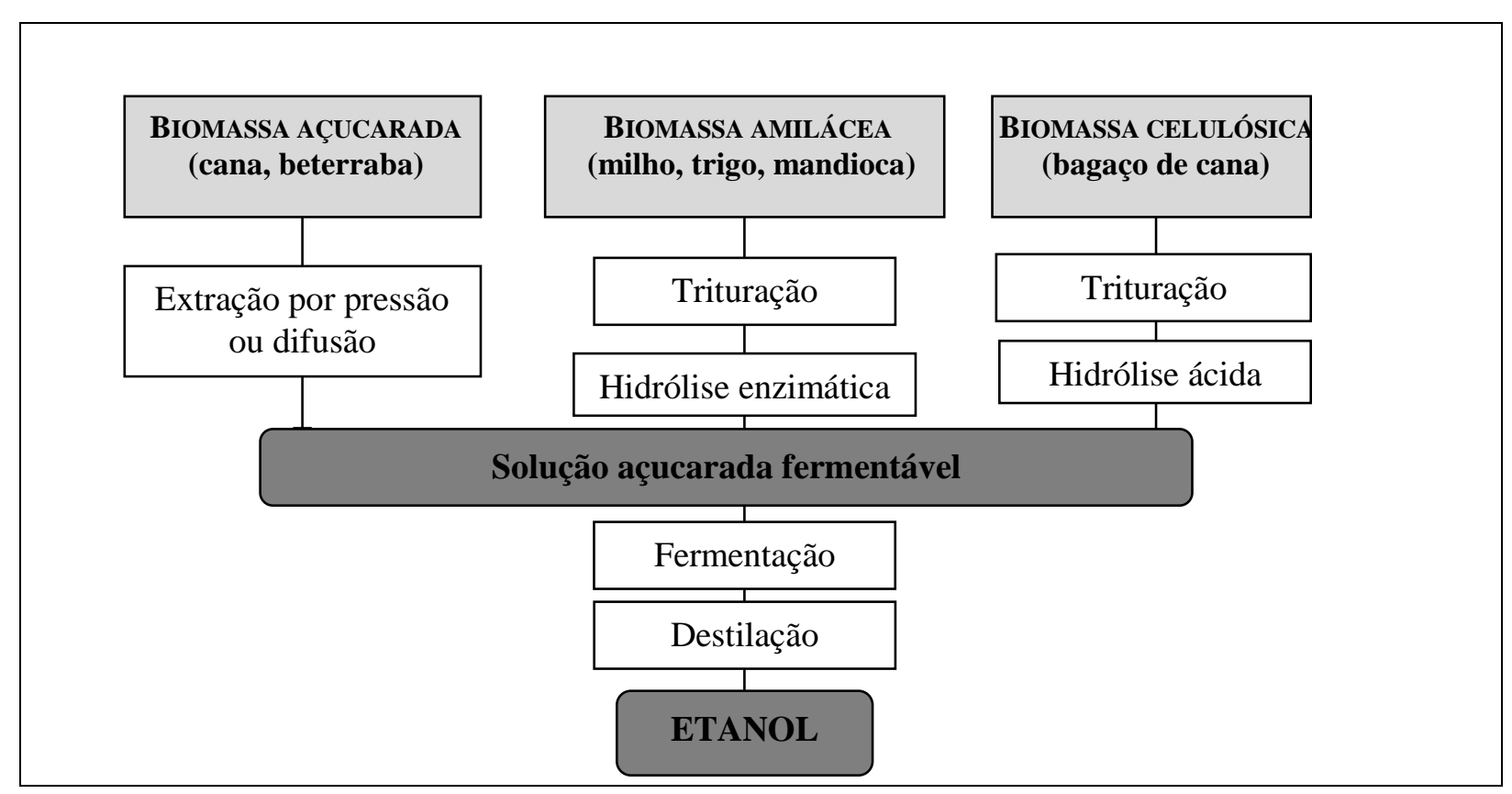

Figura 1 - Diferentes rotas tecnológicas para a produção do etanol (BNDES \& CGEE, 2008).

Cana de açúcar: o Programa Pró-Álcool (a partir de cana de açúcar) iniciado no Brasil em 1975 foi concebido para garantir o fornecimento de energia, bem como para apoiar a indústria açucareira, assim foi incentivada a construção de diversas usinas de destilarias, as quais transformavam o excesso da produção de cana de açúcar em etanol anidro, usado como aditivo (24\%) na gasolina, sem a necessidade de realizar modificações nos motores dos veículos (Kohlhepp, 2010; Manochio, 2014). Desse período em diante, foi registrada uma enorme expansão das áreas cultivadas com cana de açúcar e consequente o aumento de produção. Isso aconteceu, sobretudo, nas regiões principais de cultivos do estado de São Paulo. Em alguns municípios, a área plantada com cana de açúcar, ocupava mais de $60 \%$ da área cultivada, sendo que de 1975/1976 até 1984/1985, a produção de etanol aumentou em 20 vezes, alcançando 12 bilhões de litros (Harrison et al., 2004; Gurgel, 2011). As Tabelas 1 e 2 apresentam a produção e a participação dos principais países produtores de etanol e as fontes de carboidratos utilizados na 
sua produção e seus contaminantes, respectivamente.

Cana de açúcar vs. milho (Brasil vs. Estados Unidos) A produtividade do etanol no Brasil proveniente de cana de açúcar ganha destaque quando se compara a quantidade desse bio combustível obtida por unidade de área, pois possui resultados bastante superiores às demais culturas utilizadas como substrato (Leite \& Cortez, 2004).

Quando a cana de açúcar é utilizada apenas para a produção de etanol (aplicando a tecnologia brasileira), uma tonelada da cana é capaz de produzir cerca de 90 litros do combustível (Wyman, 1996). Por outro lado, a produção americana de etanol (em 2007) a partir de milho totalizou 2,8 bilhões de litros. Todavia, esta quantidade foi insuficiente para consumo interno e o país necessitou importar 1,96 bilhões de litros do etanol brasileiro (Gurgel, 2011; Manochio, 2014). Com a construção de novas usinas, os Estados Unidos vem se aproximando da autosuficiência (Cavalcante, 2010). De acordo com a Sociedade Nacional de Agricultura (2014) no ano passado foram produzidos no Brasil 11 milhões de litros de etanol provenientes de 29.000 toneladas de milho, em duas usinas localizadas no Mato Grosso. As vantagens da utilização desse grão em relação à cana de açúcar são:

a. Facilidade na armazenagem do grão (no período de entressafra da cana);

b. Excesso de produção de milho nessa região;

c. Baixo custo.

Tabela 1. Produção e participação dos cincos principais produtores de etanol.

\begin{tabular}{lcc} 
& \multicolumn{2}{c}{ Produção de etanol } \\
\cline { 2 - 3 } País & $\begin{array}{c}\text { Volume } \\
\text { (bilhões de } \\
\text { litros) }\end{array}$ & $\begin{array}{c}\text { Participação } \\
(\%)\end{array}$ \\
\hline Estados Unidos & 54,2 & 63,0 \\
Brasil & 21,0 & 24,4 \\
China & 2,1 & 2,4 \\
Canadá & 1,8 & 2,1 \\
França & 1,1 & 1,3 \\
Resto do mundo & 5,9 & 6,9
\end{tabular}

(Adaptado de REN 21, 2012)

Tabela 2. Fontes de carboidratos para produção de etanol em diferentes países.

\begin{tabular}{lcc}
\hline \multirow{2}{*}{ País } & & Matéria prima \\
\cline { 2 - 3 } África & Fonte & Contaminantes \\
Austrália & Sorgo & Agrotóxicos/micotoxinas/HPAs ${ }^{2}$ \\
Alemanha & Cana de açúcar & Agrotóxicos/HPAs \\
& Beterraba & Agrotóxicos/HPAs \\
Brasil & Cana de açúcar & Agrotóxicos/HPAs \\
Canadá & Milho ${ }^{1}$ & Agrotóxicos/micotoxinas/HPAs \\
China & Milho & Agrotóxicos/micotoxinas/HPAs \\
& Milho. & Agrotóxicos/micotoxinas/HPAs \\
Espanha & Sorgo & Agrotóxicos/micotoxinas/HPAs \\
Estados Unidos & Beterraba & Agrotóxicos/HPAs \\
França & Milho & Agrotóxicos/micotoxinas/HPAs \\
\hline
\end{tabular}

'entresafra;

${ }^{2}$ hidrocarbonetos policíclicos aromáticos

O etanol produzido a base de milho resulta em coprodutos fluídos (componentes aquosos e óleo) e sólidos (DDGS) correspondendo 30\% do grão empregado (Spiehs et al., 2002 \& Fialho et al., 2009).

\section{DDGS}

O coproduto sólido da indústria do etanol por milho, DDGS, tem sido utilizado como ingrediente na ração animal (suínos, frangos, bovinos, cães e equinos) pelo seu alto valor de proteína, fibra e energia, conferindo um alto valor agregado neste processo (Corbin et al., 1985; Brito, 2008)

\section{Obtenção}

Após a produção do etanol, onde o milho é convertido em álcool por meio da moagem seca (MS), há formação de DDGS. Na MS, após passar pelas seis etapas de processamento (moagem, maceração, cozimento, hidrólise enzimática, fermentação e destilação - Figura 2), 
os resíduos que normalmente são descartados, podem ser aproveitados (Alves et al., 2012; USGC, 2012). São centrifugados e separados em frações: hidrossolúvel (conhecida como vinhaça - utilizada como adubo orgânico), lipídica (óleo de milho) e sólida (o DDGS) (Weigel et al., 1997). Esse processamento, devido à menor necessidade de investimentos e o maior rendimento de etanol, em relação à moagem úmida (MU) é responsável por mais de $70 \%$ da produção de etanol baseado no milho. O emprego do milho como matéria prima para a produção de etanol apresenta rendimento industrial de $460 \mathrm{~L}$ de etanol anidro e $380 \mathrm{~kg}$ de DDGS por cada tonelada de grão seco inserido no sistema (Wyman, 1996).

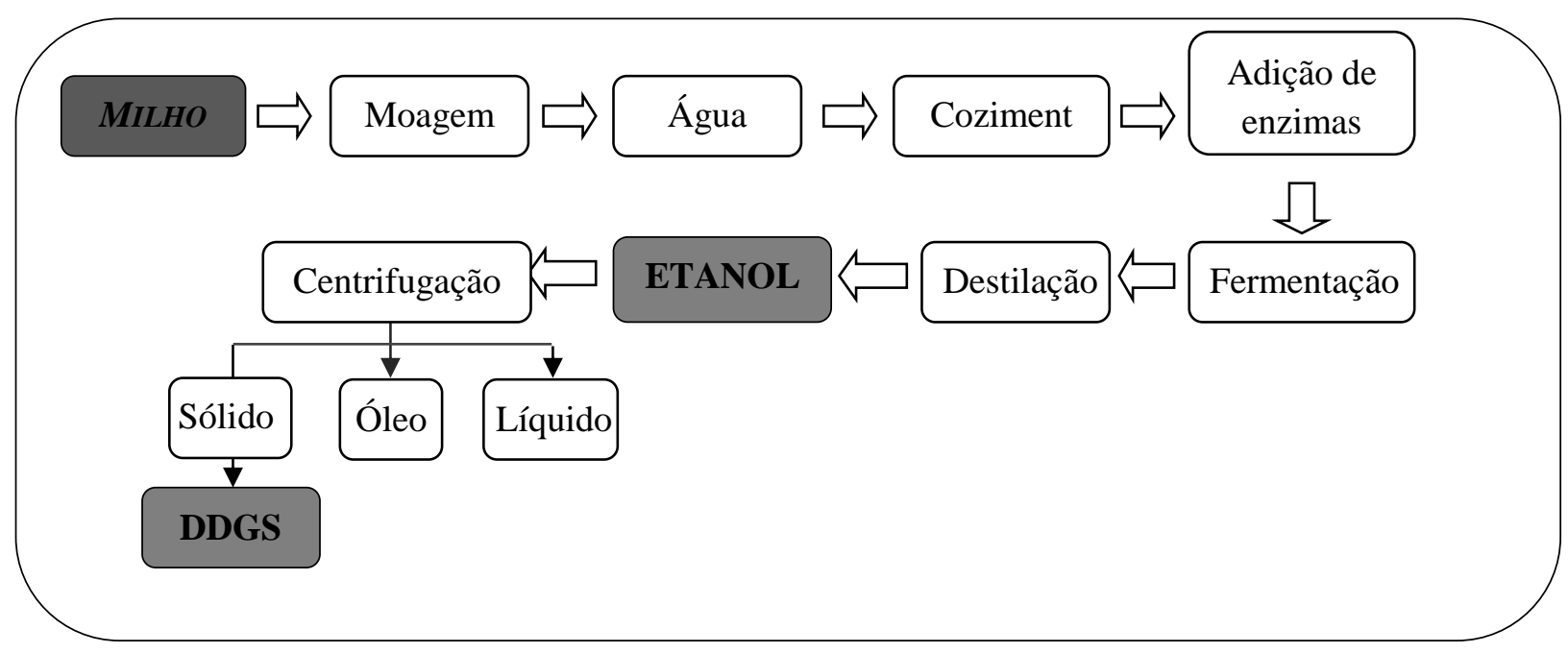

Figura 2. Processamento do etanol de milho e seus coprodutos - moagem seca (Silva, 2015)

\section{Composição nutricional}

Proteínas e fibras - o DDGS tem como característica, alto teor de proteína bruta $(30,9 \%)$ e fibra bruta $(7,2 \%)$, sendo a maior parte insolúvel. No entanto, essa composição pode variar (Tabela 3), já que depende da qualidade do milho utilizado na produção de etanol e as condições do processamento, como as diferenças no tempo e temperatura de secagem (Cromwell et al., 1993; Brito et al., 2008). Quanto às fibras, o DDGS possui teor mais elevado de fibra em detergente neutro do que em detergente ácido. Portanto, se caracteriza como coproduto de alta concentração de hemicelulose (Spiehs et al., 2002; Silva, 2015).

Tabela 3. Composição nutricional do coproduto sólido do etanol - grãos secos de destilaria com solúveis.

\begin{tabular}{|c|c|c|c|c|}
\hline \multirow{2}{*}{\multicolumn{2}{|c|}{ Nutrientes }} & \multicolumn{3}{|c|}{ Composição do $\operatorname{DDGS}^{1}(\%)$} \\
\hline & & Média & Faixa (min-max) & $\mathrm{DPR}^{2}$ \\
\hline \multicolumn{2}{|l|}{ Proteína Bruta } & 30,9 & $28,7-32,9$ & 4,7 \\
\hline \multicolumn{2}{|c|}{ Extrato Etéreo (lipídios) } & 10,7 & $8,8-12,4$ & 16,4 \\
\hline \multicolumn{2}{|c|}{ Fibra Bruta } & 7,2 & $5,4-10,4$ & 18,0 \\
\hline \multicolumn{2}{|c|}{ Fibra em detergente neutro } & 26,7 & $19,7-34,1$ & 11,8 \\
\hline \multicolumn{2}{|c|}{ Fibra em detergente ácido } & 8,4 & $6,2-13,4$ & 23,4 \\
\hline \multicolumn{2}{|c|}{ Cinzas } & 6,0 & $3,0-9,8$ & 26,6 \\
\hline \multirow[t]{3}{*}{ Aminoácidos: } & Lisina & 0,9 & $0,61-1,6$ & 11,4 \\
\hline & Arginina & 1,31 & $1,01-1,48$ & 7,4 \\
\hline & Metionina & 0,65 & $0,54-0,76$ & 8,4 \\
\hline Fósforo & & 0,75 & $0,42-0,99$ & 19,4 \\
\hline
\end{tabular}

' grãos secos de destilaria com solúveis. (Adaptado de Sphies et al., 2002; Salim et al., 2010).

${ }^{2}$ desvio padrão relativo 
Aminoácidos - alguns trabalhos relatam existir correlação entre a intensidade de cor do DDGS e a composição de aminoácidos, onde as amostras mais claras apresentam maior conteúdo de aminoácidos que as amostras mais escuras. Isso porque os DDGS durante o processo de secagem podem passar por aquecimento excessivo levando a perdas do conteúdo de aminoácidos (amostras escurecidas - degradação de proteínas) (Figura 3) (Urriola et al., 2009).

Energia - o DDGS de alta qualidade apresenta energia digestível (ED) e energia metabolizável (EM) semelhantes ou maiores que as do milho (Spiehs et al., 2002).

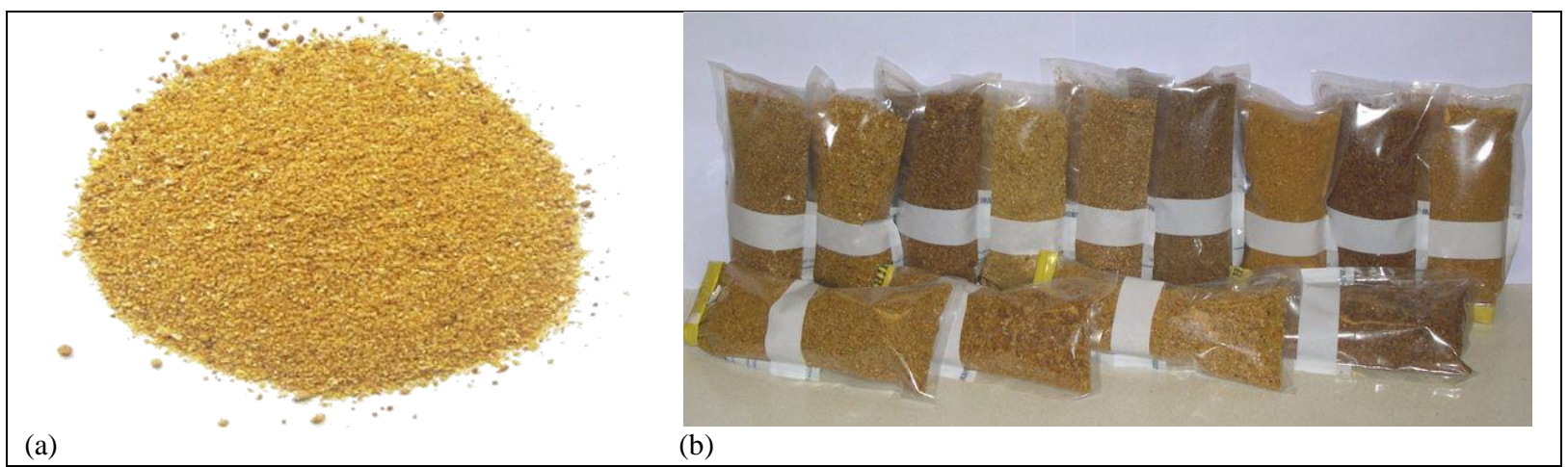

Figura 3. Grãos secos de destilaria com solúveis: (a) característica do produto; (b) variação de cor entre amostras correspondente a diferente concentração dos aminoácidos (Shurson, 2008; Sinoma, 2012).

Minerais - segundo Ribeiro (2010) um aspecto importante na avaliação nutricional desse coproduto é sua composição de macro e micro minerais, como o fósforo. O DDGS corresponde aproximadamente a $1 / 3$ do valor total do milho utilizado na produção do etanol, já que os outros 2/3 são transformados em álcool e dióxido de carbono, portanto as concentrações de minerais devem ser aproximadamente elevadas (três vezes àquelas do milho) o que pode tornar-se uma limitação no seu uso na alimentação animal (Shurson, 2008; Salim et al., 2010).

\section{Uso de DDGS nos alimentos}

O DDGS tem sido utilizado como ingredientes em alimentos para animais de produção (suínos, bovinos, aves) e de companhia (cães, gatos, equinos) (Allen et al., 1981; Ham et al., 1994; Nyachoti et al., 2005; Urriola et al., 2010), podendo também ser usado para enriquecer alimentos para humanos (Rosentrater \& Krishnan, 2006).

\section{Alimentação animal}

$\mathrm{O}$ alto crescimento e competitividade do mercado de alimentos para animais induziram a procura por ingredientes alternativos para substituir os comumente utilizados na alimentação humana, reduzindo a competitividade e barateando os custos de produção (França et al., 2011; Silva, 2015). O mercado brasileiro dispõe de grande variedade de coprodutos (farelo e casca de soja, quirera e farelo de arroz, farinha de penas, de peixe, dentre outros) que, se bem processados, poderão fornecer quantidades satisfatórias de nutrientes e energia às dietas (Hussein, 2003; Félix et al., 2012). Todavia, para que a dieta seja formulada adequadamente é importante conhecer as características nutritivas dos ingredientes, tais como, sua composição química, digestibilidade dos nutrientes, fatores anti nutricionais, toxidez e, principalmente, valor de EM (Tortola, 2011; Félix et al, 2012; Pacheco, 2013). Em virtude de sua composição nutricional e baixo custo, o DDGS passou a ser de grande importância na inclusão em dietas para diversas espécies animais em substituição parcial ao milho e soja nos Estados Unidos (Lumpkins et al., 2005; USGC, 2012). Contudo, ainda pouco conhecido e utilizado no Brasil (Silva, 2015).

\section{a. Suínos}

A alta energia (3.674 a $4.336 \mathrm{kcal} \mathrm{EM} / \mathrm{kg}$ na matéria seca - MS), proteína moderada (27 a $33 \%$, na MS), lisina $(0,60$ a $1,1 \%)$, a elevada concentração de fósforo $(0,57$ a $0,85 \%$, na MS) e alta digestibilidade (50 a $68 \%$ ) são os principais componentes nutricionais que tornam o DDGS um ingrediente alternativo em dietas de suínos (Fastinger \& Mahan, 2006). No entanto, como qualquer ingrediente na ração, o DDGS tem algumas limitações que precisam ser melhoradas para que se possam alcançar maiores benefícios 
de desempenho e econômico quando adicionado a dietas desses animais. As limitações para o uso de DDGS (acima de 20\% de inclusão na dieta) são a redução da firmeza da gordura suína, aumento do volume de fezes, e a excreção de fósforo. No entanto, estas limitações podem ser facilmente superadas pela formulação adequada (Freitas et al., 2009).

O DDGS pode ser utilizado em dietas de suínos em todas as fases de produção. As taxas de inclusão de DDGS na dieta são de até $30 \%$ para suínos em berçário com peso superior a 7 $\mathrm{kg}$, suínos em crescimento e porcas em lactação e níveis de até $50 \%$ de inclusão na dieta para porcas em gestação (Stein \& Shurson, 2009). Gaines et al. (2006) demonstraram que leitões com peso acima de $11 \mathrm{~kg}$, alimentados com dietas contendo 15 e $30 \%$ de DDGS não apresentaram diferenças no ganho diário de peso quando comparadas ao controle (sem DDGS). A inclusão de $10 \%$ de DDGS tem sido a mais recomendada, pois, não se observa diferença no desempenho quando comparados aos suínos alimentados com dieta à base de milho e farelo de soja. Ressalva-se que inclusões de 20 e $30 \%$ podem reduzir alguns parâmetros de desempenho o qual pode ser devido à impossibilidade de encontrar a exigência de aminoácidos digestíveis (Brito, 2008). Dietas peletizadas com DDGS melhoram o desempenho do crescimento de suínos bem como a eficiência da alimentação através do aumento da digestibilidade de energia (Zuh et al., 2010). Tran et al. (2011) demonstraram que o DDGS pode ser incluído em dietas para suínos ao nível de $15 \%$ durante todo o período do berçário, ou até $30 \%$ durante o período de creche sem comprometer o desempenho de crescimento.

\section{b. Aves}

Assim como para suínos a lisina e metionina são aminoácidos limitantes e que requerem grande atenção quando se faz o uso de DDGS na ração de frangos. Salim et al. (2010) relatam que até $25 \%$ de DDGS seria o ideal para ganho de peso (GP) e ingestão alimentar. Loar et al. (2011) avaliaram efeitos no desempenho de frangos de zero a 14 dias de idade alimentados com diferentes níveis de DDGS (8, 16, 24 e 32\%). Altas inclusões de DDGS reduziram o GP e pioraram a conversão alimentar e mortalidade, a partir da inclusão de $24 \%$. Teores de lisina em dietas iniciais para frangos são um dos fatores mais preocupantes quando há a inclusão de
DDGS. A inclusão de $6 \%$ é a mais segura para a fase inicial enquanto que para crescimento e terminação a adição de 12 a $15 \%$ de DDGS é a mais aceitável para que não haja perda de GP e aumento da mortalidade (Lumpkins et al., 2004). Em galinhas poedeiras o uso de 15\% de DDGS não teve nenhum efeito sobre o peso do ovo, cor da gema e exterior ou interior da casca e qualidade dos ovos. O mesmo autor relata que este coproduto tem provado ser um ingrediente aceitável para esses animais, além de contribuir na formulação da ração por possuir um baixo custo (Parsons et al., 2006). Enzimas (aves e suínos) - recomendações de inclusão de DDGS para aves e suínos estão frequentemente associadas à adição de enzimas fibrolíticas, como fitases e xilanases (Gaines et al., 2007). A adição de enzimas apropriadas poderia reduzir a variação da qualidade nutricional das dietas e permitir uma digestão mais rápida, diminuindo a excreção fecal de nutrientes (Bedford, 2000). Trabalhos recentes têm demonstrado respostas positivas quanto à digestibilidade de nutrientes $\mathrm{e}$ ao desempenho de aves e suínos alimentados à base de milho, soja e DDGS, quando estas foram suplementadas com enzimas, carboidrases, proteases, pectinases, fitases e xilanases (Campestrini et al., 2005).

\section{c. Bovinos}

Os primeiros animais a consumirem esse resíduo na alimentação (relatado há cinco décadas) foram os bovinos. Devido a sua composição nutricional altamente fibrosa ele auxilia na saúde ruminal, além de possuir alto valor protéico não degradável no rúmen $\mathrm{e}$ aceitabilidade, além de ser uma excelente fonte de minerais (Weigel et al., 1997). Engel et al. (2008) testaram por dois anos o uso de casca de soja e DDGS na alimentação de novilhas, 190 dias antes do parto e durante a lactação. Os autores observaram que houve uma melhora no GP nos animais alimentados com DDGS. Já os parâmetros peso ao nascimento, peso ao desmame e escore de condição corporal, não houve diferença. A ocorrência de ciclo estral pós desmame foi observada em maior porcentagem nas novilhas que consumiram DDGS. Em trabalhos em vacas leiteiras, foram testados os níveis de 22, 32 e $42 \%$ de DDGS na dieta. A maior produção de leite $(24,0 \mathrm{~kg})$ foi com a inclusão de $32 \%$. Já com $42 \%$, houve um declínio na produção diária. $\mathrm{O}$ mesmo trabalho ainda avaliou a composição nutricional do leite, 
observando que a porcentagem de sólidos teve seu maior número na dieta sem DDGS (controle) e a quantidade de gordura atingiu a maior porcentagem com a inclusão de $32 \%$ de DDGS na dieta. Já a proteína e lactose foram maiores tanto nas dietas controle quanto na com $22 \%$ de inclusão de DDGS e não diferiram entre si (Quirós et al., 2009).

\section{d. Animais de companhia}

Diferente dos animais de produção, o uso de DDGS na alimentação desses animais incluindo os cães tem sido pouco estudado. Trabalhos com gatos não foram encontrados na literatura e com cães são escassos. No entanto, a composição nutricional desse coproduto é de grande interesse na alimentação desses animais, pela sua composição protéica elevada (Silva, 2015). Allen et al. (1981) realizaram dois testes com baixas (4, $6,8 \%)$ e altas $(14,1 ; 15,7$ e $26.1 \%)$ inclusões de DDGS em dietas para cães. Os níveis baixos não afetaram a digestibilidade da MS, em contrapartida, a inclusão de $15,7 \%$ reduziu a digestibilidade da MS sem afetar a energia. Com $26,1 \%$ de DDGS na dieta houve uma redução na digestibilidade da proteína bruta (PB). Em nenhum momento os autores relatam o uso de enzimas que poderiam ajudar a aumentar a digestibilidade da proteína já que maior parte desta está ligada a hemicelulose. Em estudos com cães filhotes a inclusão de até $10 \%$ de DDGS promoveu alta aceitabilidade. A quantidade de ração ingerida foi maior nas dietas que continham o resíduo de destilaria promovendo um maior GP, isso devido ao alto valor de extrato etéreo (EEA) contido no DDGS (Corbin et al., 1984). Weigel et al. (1997) relataram que a inclusão de $25 \%$ de DDGS é o ideal para cães adultos devido ao alto valor de fibra bruta beneficiando a saúde do trato gastrintestinal e a perda de peso. Silva (2015) avaliou inclusões crescentes de 6, 12 e $18 \%$ de DDGS, em substituição a farinha de vísceras e milho da fórmula, com e sem adição da enzima xilanase, quanto à digestibilidade das dietas, características fecais e palatabilidade. A autora observou que os diferentes níveis de DDGS promoveram redução linear da digestibilidade do EEA, energia bruta e EM. Entretanto, para o coeficiente de digestibilidade aparente da $\mathrm{PB}, \mathrm{MS}$ e matéria orgânica houve a manutenção da digestibilidade das dietas com suplementação de enzima xilanase. Para características fecais não houve diferença no escore fecal, entretanto houve redução no $\mathrm{pH}$ com o aumento da inclusão de DDGS. Quanto a palatabilidade, a inclusão de $18 \%$ de DDGS teve uma boa aceitabilidade, tendo esta dieta maior consumo pelos cães. Mostrando ser um interessante ingrediente na inclusão de dietas para esses animais.

\section{Alimentação humana}

Há poucos trabalhos utilizando o DDGS na alimentação humana. No entanto, o DDGS tem potencial único para usos alimentares comerciais, particularmente em produtos de panificação (Bookwalter et al., 1984). O DDGS consiste de amido resistente, além das proteínas, fibras e lipídios insaturados (WU, 1994). Esse coproduto tem componentes que o tornam potencialmente valioso como ingrediente para alimentos humanos, pois contém ácidos graxos poliinsaturados, além de antioxidantes, ácidos fenólicos e fibra dietética (Gallaher, 2013). Liu et al. (2011) estudaram a inclusão de DDGS no pão de milho.Os autores reportaram que o elevado conteúdo de proteínas e fibras desse coproduto enriqueceu os valores nutricionais do alimento, bem como proporcionou uma dieta mais saudável para os consumidores que procuram por uma alimentação de baixo índice glicêmico e rica em fibras dietéticas.Os mesmos autores verificaram também que o conteúdo de proteína no pão de milho aumenta à medida que a porcentagem de DDGS nas formulações aumenta. A presença de DDGS nas formulações de pão de milho geralmente induz a aparência mais escura.

Há uma questão importante relacionada à incorporação do DDGS em produtos alimentares para humanos que é sua segurança. Esse coproduto do etanol possui um potencial maior de exposição à contaminante por concentrar os provenientes da matéria-prima ou serem formados no produto final, sendo um grupo deles as micotoxinas (Murphy et al., 2006). Sua formação pode ocorrer devido à contaminação fúngica durante o armazenamento dos grãos e do próprio coproduto (Kahtibi et al., 2014).

\section{DDGS e a segurança alimentar}

A segurança alimentar tem um impacto significativo no nosso sistema global de alimentos. A contaminação afeta toda a cadeia alimentar e custam milhões em receitas perdidas e aumenta os custos. Além disso, desenvolve temor e pânico entre os consumidores, reduz a quantidade de alimento disponível para $\mathrm{o}$ consumo e a confiança dos consumidores no 
sistema alimentar (USGC, 2012).Ainda que o risco de contaminantes no DDGS possa ser baixo, os Estados Unidos aprovaram recentemente os regulamentos mais rigorosos de segurança alimentar, incluindo a produção de DDGS, a fim de minimizar ainda mais os riscos para consumidores. $\mathrm{O}$ monitoramento exigido nas usinas de etanol inclui o teste de entrada de grãos para DDGS, como micotoxinase contaminação microbiana (USGC, 2012)

\section{Fatores que favorecem a contaminação de $D D G S$}

A prevalência de fungos e micotoxinas em alimentos é uma preocupação permanente em muitos países. Historicamente, sua prevalência na safra de milho dos Estados Unidos é menos frequente e na maioria, abaixo dos limites estabelecidos (Spiehs et al., 2002; UCGC, 2012; Khatibi et al., 2014). As micotoxinas são produzidas por gêneros de fungos específicos (Aspergillus, Penicillium e Fusarium) quando há condições ambientais favoráveis como, tempo úmidos e quentes e durante o crescimento da planta ou armazenagem do grão de milho (Scussel, 2002; Caupert et al., 2011).

No Brasil, (nas regiões tropicais e subtropicais) existem condições propícias para o crescimento de fungos produtores de micotoxinas (Maziero \& Bersot, 2010), devido ao clima quente e úmido predominante nessas regiões. Além do fator climático, o sistema de produção tem elevados índices de perdas de qualidade de grãos (Brasil, 1992; Palacin et al., 2006). O crescimento fúngico e a formação de micotoxinas são dependentes de uma série de fatores, como umidade, temperatura, presença de oxigênio, tempo para o crescimento fúngico, constituição do substrato, características genéticas, lesões à integridade dos grãos causados por insetos ou dano mecânico, quantidade de inóculo e interação/ competição entre as linhagens fúngicas (Scussel, 1998; 2002; Queiroz et al., 2009). Além desses fatores, as condições de secagem e armazenagem também são fatores envolvidos no desenvolvimento de fungos (Lorini, 2002; Silva et al., 2008).

Em relação às bactérias, estas podem estar presentes durante a fermentação do milho para a produção de etanol, devido às condições do processamento como altas temperaturas e umidade (Bischoff et al., 2009; Heist, 2009). O que preocupa no DDGS não são só os fatores que favorecem a contaminação no milho, mas também a secagem incorreta do DDGS após o processamento de etanol e o ambiente em que esse coproduto pode ser armazenado os quais são de grande relevância para a contaminação por agentes microbiológicos (Zangh et al., 2009).

\section{Tipos de contaminantes}

Dentre os contaminantes que podem estar presentes no DDGS, estão aqueles que se desenvolvem/formam durante o cultivo da matéria-prima da indústria (milho, trigo, cevada, cana de açúcar, beterraba) do etanol, as quais podem permanecer (resistentes a temperatura) ou se concentrar no produto final sólido. Assim como serem formados durante a secagem e/ou armazenamento deficientes. São eles, de campo [matéria prima]: fungos, agrotóxicos, HPAs e micotoxinas, durante a produção: antibióticos e/ou pós-produção [DDGS]: fungos, bactérias, toxinas, HPAs (Bischoff et al., 2009; Zangh et al., 2009; Kahtibi et al., 2014).

\section{a. Microbiológicos}

1. Fungos toxigênicos - como todos os ingredientes de alimentos, os grãos de destilaria, assim como o milho usado no processamento,podem conter, por vezes, quantidades de fungos toxigênicos que podem afetar negativamente o desempenho dos animais (Whitney \& Shurson, 2004). Esses fungos são produtores de micotoxinas, que provocam grandes perdas econômicas em toda a cadeia produtiva agrícola, e à saúde humana e animal. As principais micotoxinas produzidas por gêneros Fusarium, Aspergillus e Penicillium são relatadas em milho são as fumonisinas (FBs), zearalenona (ZON), deoxinivalenol (DON), ocratoxina A (OTA), toxina T-2 e as aflatoxinas (AFLs) (Scuessel, 1998, 2002; Queiroz et al., 2009). Já no DDGS as principais micotoxinas relatadas são a DON e FBs (Zangh et al., 2009; Khatibi et al., 2014).

2. Bactérias: outro grupo de contaminante microbiológico que pode estar presente no DDGS são as bactérias. A contaminação ocorre durante a fermentação, Lactobacillus, Pediococcus e Leuconostoc, produtoras de ácido lático, são as mais comuns (Bischoff et al, 2009; Muthaiyan \& Ricke, 2010). Essas bactérias são de grande preocupação porque competem com a levedura, que produz amido, por crescimento (Skinner \& Leathers, 2004). Bactérias produtoras de ácido lático são problemáticas porque podem suportar 
temperaturas elevadas e $\mathrm{pH}$ baixo, condições encontradas no processo de produção de etanol. Além disso, essas bactérias crescem rapidamente e atingem um elevado número de células viáveis antes da conclusão da fermentação de levedura (Leja \& Broda, 2009). A contaminação bacteriana reduz o rendimento de etanol até $5 \%$ e resulta na produção de DDGS com qualidade inferior (Narendranath et al., 1997). As bactérias também deterioram o DDGS e levam a alteração no flavour e possível rejeição pelos animais (Salim et al., 2010; USGC, 2012).

\section{b. Químico}

1. Antibióticos: esses compostos têm sido utilizados para controlar a proliferação bacteriana durante a fermentação da produção de etanol por muitos anos (Juranek \& Duquette, 2007). Os mais utilizados são asvirginiamicina, tetraciclina, eritromicina e penicilina. Quando os antibióticos são usados, eles são adicionados na fermentação em quantidades muito pequenas em relação às taxas de utilização em alimentos para animais (USGC, 2012). Existem duas principais preocupações com o uso de antibióticos na produção de etanol. O primeiro é o potencial para que as bactérias desenvolvam resistência, tornando ineficazes os antibióticos para controlar as infecções (Muthaiyan \& Ricke, 2010). Em segundo lugar, há uma preocupação sobre o resíduo de antibiótico no DDGS, que é largamente utilizado na alimentação animal, e consequentemente, o resíduo nos tecidos animais para consumo humano (Benz, 2007). PaulusCompart (2012) concluiu recentemente um estudo para determinar a presença de resíduos de antibióticos em DDGS. Um total de 159 amostras foram analisadas para tetraciclina, tilosina, eritromicina e penicilina. Uma amostra continha concentrações detectáveis de tetraciclina e uma amostra continha níveis detectáveis de penicilina, mas nenhuma das amostras continham resíduos de tilosina. Eritromicina foi encontrada em 16 amostras $(10,1 \%)$. Apenas duas amostras tinham concentrações detectáveis de virginiamicina $>0,3$ ppm (Figura IV).

2. Outros contaminantes - os resíduos de agrotóxicos também são contaminantes inerentes ao grão de milho e podem chegar aos seus coprodutos (BRASIL, 2009). O controle de resíduos de agrotóxicos em alimentos está baseado nos limites máximos de resíduos (LMRs) e no intervalo de segurança. Para garantir a segurança dos alimentos quanto ao nível de resíduos de agrotóxicos, o LMRs são definidos pela Food and Agriculture Organization (FAO), pela Comissão do Codex Alimentarius e pela World Health Organization (WHO), representando a concentração máxima de resíduo que poderá ser ingerida diariamente através da alimentação (BRASIL, 2009; Savi et al., 2014).

\section{Micotoxinas}

As micotoxinas são metabólitos secundários produzidos por uma variedade de fungos. São compostos orgânicos, biologicamente ativos, que podem causar ampla variedade de efeitos tóxicos em animais e humanos (Coulombe, 1993). São consideradas mais prevalentes no Brasil as FBs (Fusarium), ZON (Fusarium), DON (Fusarium) OTA (Penicillium e Aspergillus) AFLs (Aspergillus) (Rumbeiha, 2000; Scussel, 1998, 2002).

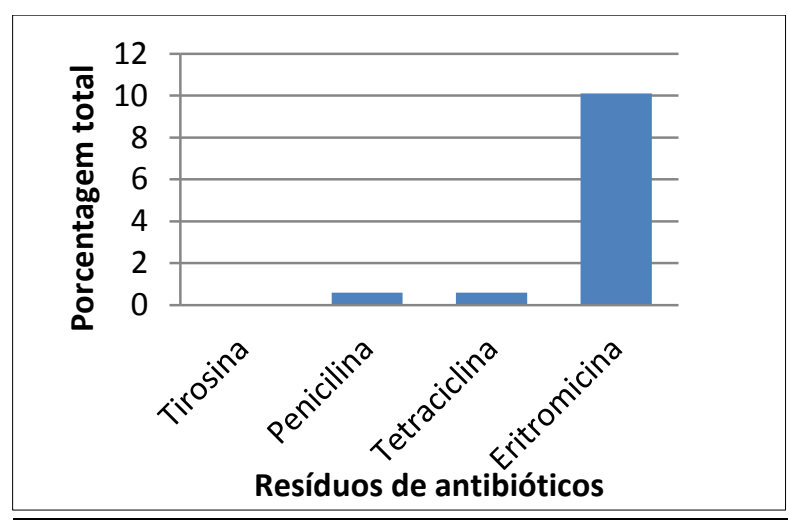

Figura 4. Porcentagem de amostras de grãos secos de destilaria com solúveis (DDGS) contendo resíduos de antibióticos (Paulus-Compart, 2012).

O efeito tóxico causado pelas micotoxinas em animais e humanos varia de acordo com a micotoxina em questão, podendo ser agudo ou crônico (Hussein \& Brasel, 2001). Enquanto algumas causam danos funcionais ao fígado e rim, outras se apresentam neurotóxicas ou interferem na síntese de proteína, causando efeitos que variam de sensibilidade cutânea a imunodeficiência extrema (Sweneey \& Dobson, 1998; Scussel 2000, 2002). Programas de monitoramento dos níveis de contaminação de alimentos por micotoxinas são essenciais para estabelecer prioridades em ações de órgãos reguladores (Scussel, 1998, 2002).

A FAO estima que mais de um quarto das culturas do mundo são afetadas por micotoxinas a cada ano, com perdas de cerca de 1 bilhão de toneladas de alimentos (Weidenborner, 2001). Estas perdas são sentidas pelos produtores de 
grãos e de animais, assim como manipuladores e fabricantes de alimentos (Khatibi et al., 2014).

As micotoxinas podem estar presentes no DDGS se o grão de milho para produção de etanol estiver contaminado com esses metabólitos ou durante seu período de armazenagem. As micotoxinas não são destruídas durante o processo de produção de etanol, nem são destruídas durante o processo de secagem para produzir o DDGS (USGC, 2012; Khatibi et al., 2014). Zhang et al. (2009) avaliaram amostras de DDGS para determinar a extensão e grau de contaminação por micotoxinas entre as fontes de DDGS nos Estados Unidos. As concentrações de todas as micotoxinas no DDGS foram abaixo do LMT pela FDA para todas as micotoxinas. No entanto, havia apenas duas amostras em que as concentrações de DON e FBs foram ligeiramente acima das recomendações para animais, e nesses casos a taxa de ocorrência foi menor que $10 \%$ de todas as amostras testadas. Trabalhos realizados relataram que as micotoxinas podem concentrarse três vezes no DDGS em relação ao grão (Schaafsma et al., 2009; Shurson et al., 2009) . O DDGS contaminado com uma única micotoxina, ou seu grupo, por exemplo, a FBs, pode contribuir para perdas na produção de suínos em US \$ 147 milhões por ano, com perdas totais que possam ser significativamente maiores quando a contaminação é por várias micotoxinas afetando mais de um animal (Wu \& Munkvold, 2008).

Patógenos do gênero Fusarium produzem micotoxinas perigosas (FBs, ZON, DON) que podem contaminar o milho ainda no campo e consequentemente o DDGS resultante desse processo. Dessas micotoxinas, o DON pode causar vômitos, recusa alimentar, e até mesmo a morte (Pestka, 2010). Khatibiet al (2014) avaliaram 141 lotes de DDGS em 12 estados dos Estados Unidos em 2011 e reportaram que a concentração de DON variou de $<0,50$ a 14,62 $\mathrm{mg} / \mathrm{Kg}$ (Tabela 4). Os mesmos autores ainda relataram que os lotes de DDGS contaminados com níveis inaceitáveis de DON foram comercializados como produtos para alimentação animal, o que mostra a importância do monitoramento dessas toxinas.

\section{Controle, prevenção e descontaminação}

$\mathrm{O}$ esforço para encontrar meios de prevenir ou controlar o crescimento de fungos e a produção e micotoxinas seja no milho como no DDGS, tem recebido cada vez mais atenção. Nos Estados
Unidos a FDA tem autoridade reguladora para todos os medicamentos, aditivos e os ingredientes usados em alimentos para animais e humanos, bem como estabelecer limites para contaminantes para a alimentação animais de produção (Heller, 2012) utilizados no processamento de alimentos de origem animal para consumo humano (Benjamin, 2009).

Tabela 4. Contaminação por deoxinivalenol em diferentes lotes de grãos secos de destilaria com solúveis

\begin{tabular}{cccc}
\hline \multirow{2}{*}{$\begin{array}{c}\text { DDGS } \\
\text { (lote) }\end{array}$} & $\begin{array}{c}\text { Concentração } \\
\left(\mathrm{mg} / \mathrm{kg}^{\mathrm{b}}\right)\end{array}$ & \multicolumn{2}{c}{ Amostras positivas } \\
\cline { 3 - 4 } & $<1,0$ & Número & $(\%)$ \\
\hline 1 & $\geq 1,0 \leq 5,0$ & 98 & 69,5 \\
2 & $>5,0<10,0$ & 36 & 25,5 \\
3 & $\geq 10,0$ & 4 & 2,1 \\
4 & & 4 & 2,8 \\
\hline
\end{tabular}

a grãos secos de destilaria com solúveis (Khatibi et al, 2014).

b deoxinivalenol

Medidas de controle também precisam ser adotadas para evitar a contaminação por fungos e micotoxinas nos grãos e DDGS armazenados tais como: secagem eficiente, manutenção do controle de umidade e temperatura durante aarmazenagem e monitoramento de fungos e micotoxinas durante todo o período. Além disso, certificar que condições adequadas no período de colheita sejam aplicadas como: evitar danos mecânicos aos grãos e realizar a colheita no ponto de maturação dos grãos, também são fatores importantes para evitar o crescimento de fungos (Scussel, 1998; Tibola et al., 2009).Já, para evitar a contaminação com resíduos de agrotóxicos, o LMR e o intervalo de segurança após aplicação dos agrotóxicos nos grãos devem ser respeitados (BRASIL, 2009; Savi, 2014).

A utilização de antibióticos para reduzir as bactérias presentes no processamento do etanol também é regulada pelo FDA, assim como, a análise de micotoxina no milho usado para a produção desse bio combustível (USGC, 2012). No Brasil, Devido ainda ao pouco conhecimento e produção de DDGS, não foram regulamentados os limites para contaminantes nesse coproduto, apenas para o milho. Além desses fatores, há a preocupação com a secagem correta do DDGS após o processamento do etanol e sua armazenagem (Zangh et al., 2009) a qual, juntamente com a contaminação ambiental do milho pode viabilizar a formação de HPAs (Garcia et al, 2013). 
Quando as medidas preventivas não são suficientes, o milho pode estar contaminado por fungos toxigênicos, micotoxinas e/ou agrotóxicos incluindo os seus coprodutos, como o DDGS, o que traz altos prejuízos a saúde animal e humana. Por isso, a descontaminação antes da utilização do coproduto/ingrediente para fins de consumo animal ou humano é de fundamental importância. Assim, métodos de descontaminação são de grande valia para evitar perdas na produção e melhorar a qualidade dos grãos (LORINI, 2002; Khatibi et al., 2014; Savi, 2014; Beber et al., 2015) descontaminação do grão pode ocorrer por meio da remoção do material contaminado ou destruição e degradação dos contaminantes (fungos, micotoxinas, bactérias e agrotóxicos). Pode ocorrer por agentes físicos (calor, microondas, raios gama e luz ultravioleta), químicos (agentes oxidantes, ácidos, bases e ozonização) e biológicos (microorganismos) (Scussel, 1998).

\section{Conclusões}

O DDGS tem sido reportado ser um bom ingrediente devido a suas inúmeras vantagens quanto à composição nutricional em aplicações para alimentação animal e humano (embora, ainda pouco estudada).

Apesar de pouco conhecido e produzido no Brasil, o DDGS pode ser uma boa alternativa para redução nos custos da dieta animal, além de diminuir o impacto ambiental desse coproduto do etanol. No entanto, deve-se ter uma preocupação quanto à qualidade na questão nutricional, que sofre grande variação, assim como na segurança (em relação aos contaminantes microbiológicos e químicos) desse produto antes de produção em larga escala e/ou o Ministério da Agricultura Pecuária e Abastecimento (MAPA) estabelecer padrões para a comercialização, bem como LMT para possíveis contaminantes.

\section{Referências Bibliográficas}

Alves, J. O; Zhuo, C.; Levendis, Y. A. \& Tenório, J.A.S. (2012). Síntese de nano materiais de carbono a partir do resíduo de milho (DDGS). Química Nova, 35:1534-1537.

Beber, M.; Savi, G. D. \& Scussel, V.M. (2015). Ozone effect on Fungi proliferation and genera susceptibility of treated stored dry paddy rice (L.). Journal of Food Safety, 35:59-65.

Bedford, M. R. (2000) Exogenous enzymes in monogastric nutrition - their current value and future benefits. Animal Feed Science and Technology, 86:1-13.

Benjamin, L. (2009) Biofuel co-products opportunities \& challenges. Food and Drug Administration, Rockville, MD, 2009.

Benz, S. A. (2007) In: J. A. Miller (ed.). Department of Health \& Human Services, Rockville, MD.

Bischoff, K. M., S. Liu, T. D. Leathers, R. E. Worthington \& J.O. Rich. (2009) Modeling bacterial contamination of fuel ethanol fermentation. Biotechnol. Bioeng.

BNDES \& CGEE. (Org.). Bioetanol de cana de açúcar: energia para o desenvolvimento sustentável. Rio de Janeiro: Bndes, 2008. 316 p. DC, 2007. Disponível em: <http://www.cei.org/pdf/5774.pdf>. Acesso em: 25 jul. 2015.

Bookwalter, G. N.; Warner, K.; Wall, J. S. \& Wu, Y. V. (1984). Corn distillers' grains and other by-products if alcohol production in blended foods. II. Sensory, stability, and processing studies. Cereal Chemistry.

BRASIL (1992). Ministério da Agricultura e Reforma Agrária. Regras para análise de sementes. Brasília: SNDA/DNDV/CLAV.

Brito, C. Uso do DDGS, um subproduto na produção do etanol, na alimentação de monogástricos. Artigo técnico Poli-Nutri alimentos. 2008.

Campestrini, E; Silva, V. T. M; Appelt \& M. D. (2005). Utilização de enzimas na alimentação animal. Revista Eletrônica Nutritime, 2:259272.

Caupert, J. Y.; Zhang, P.; Imerman, J. J.; Richard \& G. C. Shurson. (2011). Mycotoxin occurrence in DDGS. In: Distiller's Grain Production, Properties, and Utilization. Pp. 215-229. Published by Newgen Imaging Systems, Ltd.

Cavalcante, A. R. (2010) O sistema de produção do etanol: sustentabilidade e perspectivas. 2010. Trabalho de conclusão de curso (Curso de Técnico em Produção Industrial), Faculdade de Tecnologia de Taquaritinga, Taquaritinga.

Corrêa, L. C. (2006). Transformação do Álcool em Commodity. In: Simpósio internacional e mostra de tecnologia e energia canavieira. 
Coulombe, R. A. (1993). Biololgical action of mycotoxins. Journal of Dairy Science, 76:880-891.

Cromwell, G. L., Herkelman, K. L. \& Stahly, T. S. (1993). Physical, chemical, and nutritional characteristics of distillers dried grains with solubles for chicks and pigs. Journal of Animal Science.

Engel, C. L.; Patterson, H. H. \& Perry, G. A. (2008). Effect of dried corn distillers grains plus solubles compared with soybean hulls, in late gestation heifer diets, on animal and reproductive performance. Journal of Animal Science, 86.

Fastinger, N. D. \& Mahan, D.C. Determination of the ileal amino acid and energy digestibilities of corn distillers dried grains with solubles using grower-finisher pigs. Journal of Animal Science.

Félix, A. P.; Carvalho, M. P.; Alarça, L. G., Brito; C. B. M.; Oliveira, S. G. \& Maiorka, A. (2012). Effect of the inclusion of carbohydrases and different soybean meals in the diet on palatability, digestibility and faecal characteristics in dog. Animal Feed Science an Technology, 174:182-189.

Fialho E. T.; Silva H. O.; Zangeronimo, M. G.; Amaral, N. O.; Rodrigues P. B. \& Cantarelli V. S. (2009). Alimentos alternativos para suínos. Lavras: Editora UFLA/FAEPE. 232 p.

Freitas, L. S.; Azain, M. J.; Dove, C. R.; Pringle \& T. D. (2009). Effect of dietary distillers dried grains with solubles on performance and carcass characteristics in finishing hogs. Journal of Animal Science, 87.

Gaines, A. M.; Petersen; J. D. \& Spencer, N. R. (2007). Use of corn distillers dried grains with solubles (DDGS) in finishing pigs. Journal of Animal Science, 85.

Garcia, L. V.; Garcia, L. P.; Scussel, V. M. \& Resnik, S. (2013). Polycyclic aromatic hydrocarbons in milk powders marketed in Argentina and Brazil. Food Additves \& Contaminants - Part A - Chemistry, Analysis, 30:1573-1580.

Gurgel, A. C. (2011). Impactos da política americana de estímulos aos biocombustíveis sobre a produção agropecuária e o uso da terra. RESR, Piracicaba, SP, vol. 49, $n^{\circ} 01, p$. 181-214.
Heller, D. N. (2015). Analysis of antibiotics in distiller's grains using liquid chromatography and ion trap tandem mass spectrometry. 2009 Disponível em: <www.fda.gov/downloads/ AnimalVeterinary/.../UCM182280.pdf> Acesso: 05 jul. 2015.

Hussein, H. S. \& Brasel, J. M. (2001). Toxicity metabolism and impact of mycotoxins on humans and animals. Toxicology, 167:101134.

Hussein. S. H. (2003). Functional fiber: role in companion animal health. In: Production Symposium Trade Show - Pet Food Forum, Chicago - Illinois, 125-131.

Juranek, P. and P. Duquette. (2007). Antibiotic regulatory considerations for distiller's grains. Distillers Grains Quarterly, $4^{\text {th }}$ Quarter.

Khatibi, P. A.; Mcmaster, N. J.; Musser, R. \& Schmale, D. G. (2014). Survey of mycotoxins in corn distillers' dried grains with solubles from seventy-eight ethanol plants in twelve states in the U.S. in 2011. Toxins,1155-1168.

Kohlhepp, G. (2010). Análise da situação da produção de etanol e biodiesel no Brasil. Estudos Avançados, 24:68).

Leite, R. C. \& Cortez, A.B. O etanol combustível no Brasil. $2004 \quad$ Disponível em: $<$ http://www.agencia.cnptia.embrapa.br/R epositorio/etanol3_000g7gq2cz702wx5ok0wt edt3xdrmftk.pdf> Acesso em: 25 jul. 2015.

Leite, R. C. C. \& Leal, M. R. L. V. (2007). O Biocombustível no Brasil. CEBRAP.

Leja, K. \& M. Broda. (2009). The occurance and identification of microbiological contamination in fuel ethanol production. Acta Scientiarum Polonorum.

Liu, S. X.; Singh, M. \& Inglett, G. (2011). Effect of incorporation of distillers' dried grain with solubles (DDGS) on quality of cornbread. Food Science and Technology.

Loar, R.E. \& Corzo, A. (2011). Effects of varying levels of distillers dried grains with solubles on growth performance of broiler chicks. Brazilian Journal of Poultry Science, 13:279-281.

Lorini, I. Descrição, biologia e danos das principais pragas de grãos armazenados. (2002). In: Lorini, I.; Miike, L. H. \& Scussel, V. M. (Ed.). Armazenagem de grãos. Campinas: Instituto Biogeneziz, 379-397. 
Lumpkins, B.; Batal, A. \& Dale, N. (2005). Use of distillers dried grains plus solubles in laying hen diets. Journal Applied Poultry Science, 14:25-31.

Manochio, C. (2014). Produção de bioetanol de cana de açúcar, milho e beterraba: uma comparação dos indicadores tecnológicos, ambientais e econômicos. Trabalho de conclusão de curso (Engenharia Química) Universidade Federal de Alfenas. Poços de Caldas, MG.

Murphy, P. A.; Hendrich, S.; Landgren, C., \& Bryant, C. (2006). Food mycotoxins: an update. Journal of Food Science.

Muthaiyan, A., \& S. C. Ricke. (2010). Current perspectives on detection of microbial contamination in bioethanol fermentors. Bioresour Technologie.

Narendranath, N. V., S. H. Hynes, K. C.; Thomas \& M. W. Ingledew. (1997). Applied Environmental Microbiology.

Pacheco, G. F. E. (2013). Avaliação de complexos enzimáticos sobre o farelo de arroz integral e farinha de penas em dietas para cães. 2013. Dissertação (Mestrado em Zootecnia) - Universidade Federal do Rio Grande do Sul. Porto Alegre, RS.

Palacin, J. J. F.; Lacerda Filho, A. F.; Cecon, P. R. \& Montes, E. J. M. (2006). Determinação das isotermas de equilíbrio higroscópico de milho (Zeamays L.) nas espigas. Revista Brasileira de Armazenamento, 31:197-205.

Paulus-Compart, D. (2012). Fate and biological activity of antibiotics used in fuel ethanol production. M.S. Thesis, University of Minnesota.

Parsons, C.M,; Martinez, C.; Singh, V.; Radhakrishman, S. \& Noll, S. Nutritional value of conventional and modified DDGS for poultry. Multi-state poultry nutrition and feeding conference. 2006. Disponível em: <http://www.ddgs.umn.edu/prod/groups/cfans /@pub/@cfans/@ddgs/documents/asset/cfans _asset_428404.pdf>Acessoem: 15 jul.2015.

Pestka, J. J. (2010). Deoxynivalenol: mechanisms of action, human exposure, and toxicological relevance. Archives of Toxicologie.

Queiroz, V. A. V.; Santos, J. P.; Tibola, C. S. \& Queiroz, L. R. (2009). Boas práticas e sistema APPCC na fase de pós-colheita de milho. Sete
Lagoas: Embrapa Milho e Sorgo, 28 p. (Embrapa Milho e Sorgo. Circular técnica, 122).

Quirós, S. M. \& Bourrillón, A. R. (2009). Uso de granos secos conslubles (DDGS) provenientes de ladestilería del maíz em suplementos para vacas lactantes em pastoreo de estrella africana (Cynodonn lemfluensis). Agronomia Costarricense, 33:p.237-248.

REN21. (2013). Renewable Energy Policy Network for the 21st Century, Renewable Global Status Report.

Ribeiro, A. M. L., Henn, J. D. \& Silva, G. L. (2010). Alimentos alternativos para suínos em crescimento e terminação. Acta Scientiae Veterinariae, 38:61-71.

Rumbeiha, W. K. (2000). Clinical implications of mycotoxicosis in companion animals. Technical Symposium on Mycotoxin, Alltech, Inc, Nicholasville, KY.

Salim, H. M.; Kruk, Z. A. \& Lee, B. D. (2010). Nutritive value of corn distillers dried grains with solubles as na ingredient of poultry diets: a review. World's Poultry Science Journal, 66:411-432.

Savi, G. D.; Piacentini, K.; Bittencourt, K. \& Scussel, V.M. (2014). Ozone treatment efficiency on Fusarium graminearum and deoxynivalenol degradation and its effects on whole wheat grains (Triticuma estivum L.) quality and germination. Journal of Stored Products Research, 59:245-253.

Schaafsma A. W.; Limay-Rios V.; Paul D. E. \& Miller J D. (2009). Mycotoxins in fuel ethanol co-products derived from maize: A mass balance for deoxynivalenol. Journal of Science and Food Agriculture.

Scussel, V. M. (1998). Micotoxinas em alimentos. Florianópolis: Editora Insular, 144 p.

Scussel, V. M. (2002). Fungos em grãos armazenados. In: Lorini, I.; Miike, L. H. \& Scussel, V. M. (Ed.). Armazenagem de grãos. Campinas: Instituto Biogeneziz, 675-691.

Shurson, J.; Johnston, L.; Baidoo, S. \& Whitney, M. (2008). Use of dried distillers grains with soluble (DDGS) in swine diets. University of Minnesota, 144-151.

Skinner, K. A., \& Leathers, T. D. (2004). Bacterial contaminants of fuel ethanol 
production. Journal of Ind. Microbiology. Biotechnologie.

Silva, J. S.; Berbert, P. A.; Rufato, S. \& Afonso, A. D. L. (2008). Indicadores da qualidade dos grãos. In: Silva, J. S. (Ed.). Secagem e armazenagem de produtos agrícolas. Viçosa, MG: Aprenda Fácil, 63-107.

Silva, J. R. (2015). Resíduo seco de destilaria contendo solúveis (DDGS), com e sem xilanase, na alimentação de cães. Dissertação (Mestrado em Ciências Veterinárias) Universidade Federal do Paraná. Curitiba.

SNA - Sociedade Nacional de Agricultura. 2014. Disponível em: http://sna.agr.br/capaagronegocio/ Acesso em: 27 jul.2015.

Spiehs, M. J., Whitney, M. H. \& Shurson, G. C. (2002). Nutrient database for distiller's dried grains with solubles produced from new ethanol plants in Minnesota and South Dakota. Journal of Animal Science, 80:2639.

Stein, H. H. \& Shurson, G. C. (2009). BoardInvited Review: The use and application of distillers dried grains with solubles (DDGS) in swine diets. Journal of Animal Science, 87:1292-1303.

Sweneey, M. J. \& Dobson, A. D. W. (1998). Mycotoxin production by Aspergillus, Fusarium and Penicillium species. Internacional Journal of Food Microbiology, 43:141-158.

Tran, H.; Moreno, R.; Hinkle, E.E.; Bundy, J. W.; Walter, J.; Burkey, T. E. \& Miller, P. S. (2011). Effect of corn distillers dried grains with solubles on growth performance and health status indicators in weanling pigs. Journal of Animal Scienc.

Urriola, P. E, \& Stein, H.H. (2009). Effects of distillers dried grains with soluble on the digestibility of energy, DM, AA, and fiber, and intestinal transit time in a corn soybean meal diet fed to growing pigs. Journal of Animal Science, 87:145-157.

USGC, U.S Grains Council. (2012). A guide to distiller's dried grains with solubles (DDGS). Third Edition.
Weigel, J. C.; Loy, D. \& Kilmer, L. (1997). Feeding co-products of the dry corn milling process. Renewable Fuels Association and National Corn Growers Association. Washington, D.C. and St. Louis, MO, 8.

Weidenborner M. (2001). Encyclopedia of Food Mycotoxins. Springer, Berlin, Germany.

Wu F. \& Munkvold G.P. (2008). Mycotoxins in ethanol co-products: Modeling economic impacts on the livestock industry and management strategies. Journal of Agricultural and Food Chemistry.

$\mathrm{Wu}$, Y. V. (1994). Determination of neutral sugars in corn distillers' dried grains, corn distillers' dried solubles, and corn distillers' dried grains with solubles. Journal of Agricultural and Food Chemistry.

Wyman, C. E. (1996). Handbook on bioethanol: production and utilization, Applied Energy Technology Series, Taylor \& Francis, Washington.

Zhang, Y.; Caupert, J.; Richard, J.; Imerman, P. \& Shurson, J. (2009). Scientific overview of mycotoxins in DDGS. Journal of Agricultural and Food Chemistry.

Zhu, A.; Hinson, R.B.; Ma, L.; LI, D. \& Allee, G. L. (2010). Growth performance of nursery pigs fed $30 \%$ distillers dried grain with solubles (DDGS) and the effects of pelleting on performance and nutrient digestibility. Asian-Australasian Journal of Animal Science.

Recebido em Agosto 20, 2015

Aceito em Outubro 1, 2015

License information: This is an open-access article distributed under the terms of the Creative Commons Attribution License, which permits unrestricted use, distribution, and reproduction in any medium, provided the original work is properly cited 